\title{
Gifts from friends and strangers: A study of mobile music sharing
}

\author{
Maria Håkansson ${ }^{1}$, Mattias Rost ${ }^{1}$ and Lars Erik Holmquist ${ }^{1,2}$ \\ ${ }^{1}$ Future Applications Lab, Viktoria Institute, Göteborg, Sweden \\ ${ }^{2}$ Swedish Institute of Computer Science (SICS), Stockholm, Sweden \\ \{mariah,rost\}@viktoria.se,leh@sics.se
}

\begin{abstract}
Mobile technology has turned the traditionally collective activity of enjoying music into an often private one. New technologies such as wireless ad hoc networks have the potential to re-connect listeners who are now separated by headphones. We report on a field study of Push!Music, a novel mobile music sharing system. Push!Music allows both manual and automatic sharing of music between users through ad hoc wireless networking, and also provides a social awareness of other users nearby. The system was used by 13 subjects for three weeks. In post-study interviews, we identified four categories of results: social awareness, sharing music with friends, sharing music with strangers, and sharing automatically. Based on this, we present implications for design that can be applied not only to mobile music sharing systems, but to mobile media sharing in general: Allow division into active and passive use; enhance the awareness of who, where and when; support reciprocity; and finally, support identity and impression management.
\end{abstract}

\section{Introduction}

Enjoying and creating music is often a collective activity - people play in bands and orchestras, visit concerts, and dance together to music at clubs. Music fills a number of social functions, and plays an important part in how we identify and express ourselves (DeNora, 2000; O'Hara and Brown, 2006). Sharing music with others is an essential way to expand the listener's horizon and often also fills a 
social function, whether it is done through physical mix-tapes (D'Arcangelo, 2005) or using computer software such as iTunes (Voida et al., 2005).

Thanks to portable radios, Walkmans and iPods, music has become a constant companion that gives us a personal soundtrack to our everyday life (Bull, 2000; Bull, 2006). At the same time, this mobile technology has turned music listening into a private activity - we listen in isolation while in our car, in public transport and at work. It might be that this private music sphere breeds a disconnectedness, even isolation, from others even when sharing the same physical space.

Emerging wireless technology such as $\mathrm{WiFi}$ and Bluetooth could create new possibilities of sharing music in the mobile setting - essentially turning a private activity back into a social one. We argue that mobile music sharing, and more generally mobile media sharing, still has a lot of untapped potential. The telecom industry wants to find new ways for people to share personal media such as photos, songs, and video; thus driving revenue in networks and terminals. For computer-supported collaborative activities, easier sharing of multimedia files in the mobile setting could heighten social awareness, facilitate communication, and support community discourse. However, services such as MMS (Multimedia Message Service) have so far not met any great success (Jaques, 2006). To construct successful systems there is a need to explore the emerging practices around mobile media sharing.

In this paper, we report from a 3-week field study of a novel mobile music sharing system, Push!Music (Håkansson et al., 2007; Jacobsson et al., 2005). Push!Music is implemented on handheld computers which connect wirelessly through ad-hoc networks. The system allows two ways of sharing music. Firstly, users can manually send songs as personal recommendations to other users in the vicinity. Secondly, songs can automatically copy and recommend themselves to other nearby users based on a similar music history. The system also provides users with a minimal social awareness resource by displaying the nicknames of other users in the vicinity. In the study we found a number of design implications for how to design not only mobile music sharing systems, but also mobile media sharing systems in general.

\section{The Push!Music system}

Push!Music is a mobile music player with ad hoc wireless sharing capabilities that allows music to be shared between users who are in the vicinity of each other (Håkansson et al., 2007; Jacobsson et al., 2005). It has been implemented on handheld computers with wireless networking (WiFi). In its basic function, the software provides a straightforward music-playing interface with standard controls.

To facilitate music sharing, as soon as another user is anywhere within the WiFi range of a Push!Music device, s/he is shown in the interface as a connected 


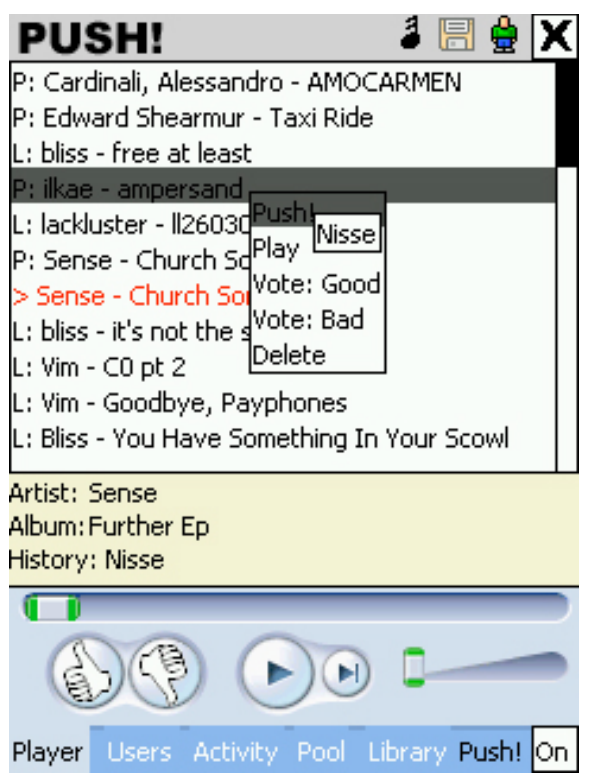

Figure 1. The Push!Music interface. user, identified by a personally selected nickname. In the main window (Figure 1) users can see at a glance if other users are nearby by checking the colour of a small icon. By switching views to a user list in the interface, users can see all currently connected persons listed by nicknames.

Music can be shared in two ways; both as a form of recommendation and as the copying of a specific song (i.e. MP3 file) from one device to another. The first way of sharing music is to manually send or push a song. Users can push songs to any nearby user who appears connected in the interface. Whenever a new song is transferred to another device, it is placed in a temporary pool of incoming music.

After the current song has finished playing, the songs from the pool are automatically played one after the other in the playlist. While a song is playing, a history list of the most recent 'owners' of this song is displayed in the interface.

The second way of sharing is that songs automatically copy themselves to nearby players, based on collected information about a user's listening history. Each song is a so-called media agent that records and saves what happens to it and in what listening context it appears (for details see Håkansson et al., 2005; Jacobsson et al., 2006). For instance, a song will know if it has been pushed and to whom, if it is being listened to frequently, if it has been explicitly rated by the user (who can click 'good' or 'bad' in the interface), etc. Each song then uses this information to compare itself with songs on other devices. If the conditions on another device are satisfactory, the song automatically starts copying itself to the new device. This happens primarily with other nearby players that have a similar listening history, but not already a copy of this particular song.

Peer-to-peer file sharing inevitably brings up the question of legal rights. As a research prototype, Push!Music currently has no digital rights management (DRM) and no payment facilities integrated into the system. However, there are several DRM systems that are designed to facilitate legal peer-to-peer sharing, for instance the Potato system (www.potatosystem.com), Weedshare (www.weedshare.com) and Snocap (www.snocap.com).

\section{Related work}

While awareness was not initially a major function of the Push!Music system, its importance was accented in our study. Dourish and Bellotti (1992) defined 
awareness as "an understanding of the activities of others, which provides a context for your own activity". Awareness technologies have typically been designed to support users of distributed collaborative work systems (e.g. in the form of Mediaspaces; Bly et al., 1993). In addition to sharing work data, such systems improve the awareness of users engaged in informal or non-work activities, with the argument that socialising, coordination, etc. are also important for the success of collaborative work systems. Peripheral awareness has also been used in other domains than work, exploring more ambiguous ways of conveying a sense of presence, for instance between remote lovers (Gaver, 2002). Presence awareness has further been an essential part in instant messaging (IM) systems where the status bar is often used to convey activity information (e.g. Grinter and Palen, 2002). A recent commercial system, Twitter, takes this to the logical extreme by in essence being an IM statusbar without any IM functionality (www.twitter.com).

Mobile awareness systems make it possible to provide awareness to users in the mobile setting. The Active Badge (Want et al. 1992) was an infrared device worn as a badge and detected by beacons in the ceiling, which made it possible to accurately detect a person's position in an office and communicate this information to other workers. The Hummingbird (Holmquist et al., 1999) required no infrastructure, and instead used mobile devices with radio transceivers to alert users when others were nearby, thus supporting social awareness. The Hummingbird was tested in a group of ski instructors during a one-week ski trip, which showed that when a system provides for such openended use, it becomes important for users to collectively negotiate when and in which situations to use it (Weilenmann, 2001).

A number of other mobile systems have been designed to increase the awareness of and trigger interaction with other users with similar profiles, for instance the Meme Tag (Borovoy et al. 1998), Social Serendipity (Eagle and Pentland, 2005) and Scent (Jung et al., 2006). In Scent, users can also exchange information about one's shared acquaintances. These systems have primarily been tested in conference settings or other events with a limited time-span. Paulos and Goodman (2004) took a different approach in Jabberwocky, an experimental system that detects and records over time the presence of so-called familiar strangers in our everyday life and then present it in an abstract way.

In the fields of CSCW and HCI, the research on music sharing and related practices has so far investigated primarily stationary or online sharing. This includes how people use online peer-to-peer file-sharing software (Brown et al., 2001), how an interactive music system could allow people to collaboratively choose music for a public place such as a café bar (O'Hara et al., 2004) or a gym (McCarthy and Anagnost 1998), and the social practices around iTunes music sharing (Voida et al., 2005). 
Several systems have also been designed to facilitate mobile music sharing in order to turn the usually private listening on mobile music devices into a more social experience. In tunA (Bassoli et al., 2006), music was streamed between devices over a wireless ad hoc network, allowing nearby users to actively "tune in" and eavesdrop on nearby users' playlists. In SoundPryer (Östergren et al., 2006), music was automatically streamed between encountering cars to create a shared music experience in traffic. Both these systems were only tested in short field trials, and unlike Push!Music did not allow for neither active nor autonomous recommendations or the copying of files between devices.

A recent commercial mobile music sharing system is Microsoft's Zune (www.zune.net), which allows users to wirelessly send songs to people in the vicinity, much like Push!Music, but without support for automatic sharing. A digital rights management (DRM) system allows the recipient to listen to the shared songs three times within three days for free. Songs can later be bought from an online music store. Users manage privacy by turning the wireless on and off, changing the privacy settings to control if other users should be able to see them online, or simply block other Zune devices from sending songs.

The study reported in this paper is the second of two consecutive user studies of Push!Music. A preliminary study was conducted in 2005 and involved a group of five male friends who used the system daily for two weeks, mostly on a local university campus (Håkansson et al., 2007). In this group, the sharing of music was playful and triggered discussions about music. Friends pushed songs as recommendations or to disseminate particular songs they liked. They highly appreciated the automatically received songs, which they considered to be unexpected and spontaneous. Finally, we found that received songs could be viewed as 'gifts', much like SMS messages sent between teenagers on mobile phones (Taylor and Harper, 2002).

\section{Method}

We conducted a three-week field study of Push!Music, where the participants used the system in their everyday life. Below we present the set-up of the study.

\section{Participants}

The study involved 13 participants: 4 women and 9 men, all students in their early- to mid-twenties recruited from a local university campus. We knew that there is limited interaction between the classes at this particular campus, and therefore deliberately recruited people from several different classes and grades. This meant that all participants knew someone or a couple of people from his/her class but not the participants from the other classes/grades (see Table I). The participants Al-A4 knew each other from class and socialised on campus; B5 and 


\begin{tabular}{lll}
\hline Group 1 & Group 2 & Group 3 \\
\hline A1 (M) & B5 (M) & D9 (M) \\
A2 (M) & B6 (M) & D10 (M) \\
A3 (F) & C7 (F) & D11 (M) \\
A4 (F) & C8 (F) & D12 (M) \\
& & D13 (M) \\
\hline
\end{tabular}

Table I. Overview of users. The participants belonged to four university classes, A-D, and were divided into three group interviews $1-3 . \mathrm{M}=$ male, $\mathrm{F}=$ female.

$B 6$ went to the same large class and knew each other by face, but did not know of each others' participation in the study; $C 7$ and $C 8$ formed a very tight pair that met every day on campus and occasionally elsewhere; and $D 9-D 13$ were a close group of friends from class who also occasionally socialised off campus. During the study we did not to reveal who the other participants were.

\section{Setting}

The campus is a four-storey building with classrooms and various open areas for group work and socialising. Many students use the open areas to meet for group projects. The campus is small enough for the participants to encounter each other by coincidence on a more or less daily basis, yet large enough to prevent students from knowing everyone beforehand. Most of the students use the same local transport line to get to and from school, which meant that it would also be possible to encounter other Push!Music users outside the main building.

\section{Procedure}

Before the study, each participant was introduced to the overall concept and functionality of Push!Music in individual pre-study meetings. Everyone was equipped with a mobile device with Push!Music installed and a set of earphones. Each participant had selected roughly 100 songs as an initial music collection to be loaded onto the personal mobile device. They were thus not explicitly familiar with each other's music before the study. The participants were told to use Push!Music as they pleased, but were encouraged to use it as their main mobile music listening device during the study. They agreed to not change the music library on their device by adding or removing songs.

During the study we regularly met up with the participants in brief feedback and support sessions to check if any technical problems had occurred. At the same time we documented spontaneous comments and questions as well as our own observations by taking notes. For example, we realised that the instability of the ad hoc network sometimes limited the music sharing. As the participants moved around or sat in different places, the indoor architecture of floors and thick walls became obstacles that made the ad hoc network rather unstable. B6, for instance, 
who was the only one on the fourth floor using the system, occasionally saw other participants and also successfully pushed a couple of songs, but did not receive any songs during the study. Quantitative data such as the amount of time using Push!Music, the number of pushed and automatically sent songs, etc., was gathered during the study by logging events in each mobile device. The media agents' individually saved information also provided us with logged data.

After the study, we performed group interviews where the participants openly discussed their experiences of using Push!Music. Before each interview, we briefly analysed relevant log data to get an initial understanding of their use of the system. All in all we ran three group interviews with 4-5 participants in each that lasted between 50 and 80 minutes. The participants took part in an interview according to university class, so that they would know someone there (see Table I). We occasionally used open-ended questions as prompts to trigger their discussions or to follow up on things they were talking about, but most of the time the authors remained in the background. The open-ended questions were for example related to what they did in general with Push!Music, if they shared any music and if yes, why, and if they had seen other users and how this had affected their usage. The participants themselves brought up several topics, such as identity, impression management and privacy.

The group interviews were recorded for transcription and analysis. The analysis consisted of categorising the raw data, and finding repeated themes, issues and also conflicting ones. In parallel, we examined the quantitative data as well as the informal notes taken during the study. All user quotes in this paper have been translated from the native language.

\section{Results}

We will first give an overview of some factors that affected the overall use of Push!Music during the study. Thereafter, we will present four themes of qualitative findings: social awareness, sharing music with friends, sharing music with strangers, and sharing automatically.

The participants used Push!Music to and from campus (by bus, ferry and bike) and on campus when their class activities allowed them to do so. Some participants temporarily replaced their personal MP3-player with the Push!Music player during the three weeks, while others used both. Several users brought up the poor battery lifetime (due to the drain of WiFi and MP3 playback) and described how they tried to remember and plan for re-charging. This implied that they used it less often on the move than they had wished for, and more often in a 'semi-stationary' way on campus where they were close to power outlets.

Since the participants had different daily schedules, the use of the system naturally became spread out over time and place. Some users encountered each other daily, while others never met during the study. For instance, C7 and C8 


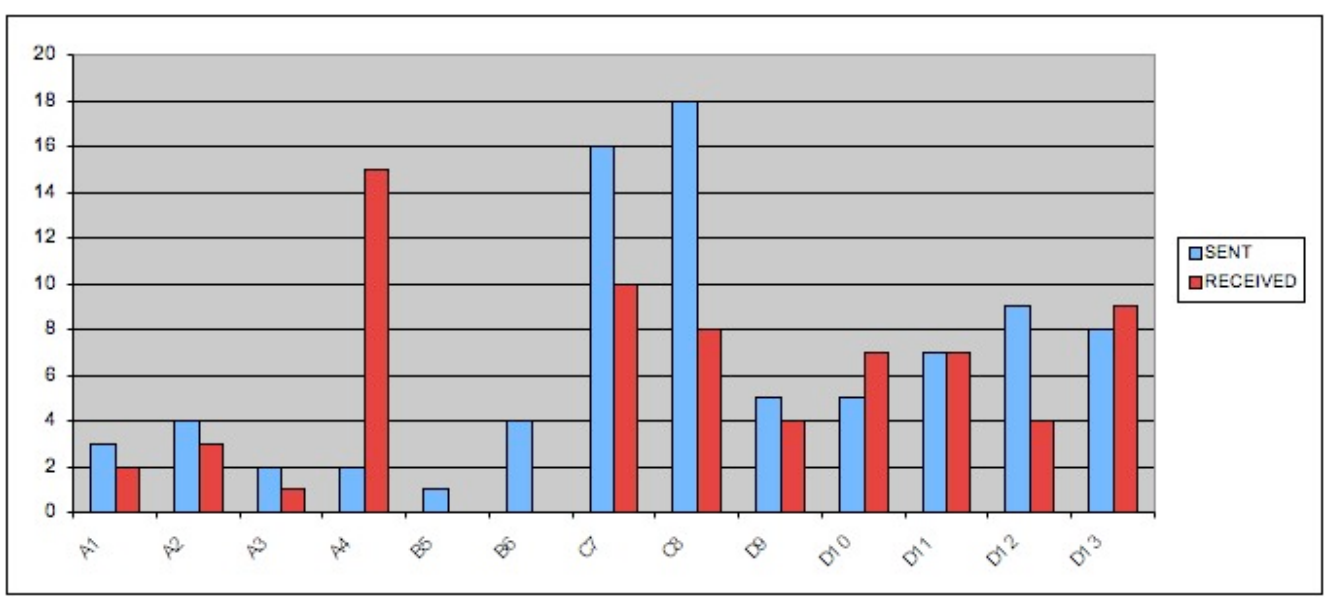

Table II. The amount of sent and received songs for each participant.

used Push!Music together in the same location on campus almost every day but not on the local transport, whereas B5 only used it to and from campus because it was his opportunity to listen to music during the day. In this way, C7 and C8 encountered more participants and shared more music than B5 who only briefly encountered another participant as he was walking to the bus stop.

After talking to the participants and analysing the logfiles, we discovered that the system had not identified enough similar music on the different players to trigger any automatic sharing. For this to happen, it is not enough to just have Push!Music on; users need to listen to a lot of music on their players, in particular songs that others have pushed to them, so that songs get a similar listening history. A combination of circumstances - the number and kind of songs pushed between groups, not always listening to music (because of other activities) and each user only encountering a sub-set of participants - had a stronger than expected impact on the automatic sharing. Despite this, the participants had very valuable opinions about the concept of automatic sharing.

The number of manually sent (pushed) and received songs for each participant is presented in Table II. During the 3-week period, users sent 84 songs and received 70 (the difference can be explained by lost transfers due to bad network connections, e.g. if a user moved out of range while a song was being transferred). The table shows some clear differences between the groups. A1-A4 socialised on campus and primarily explored the system together. A4, however, spent more time on campus working alone with Push!Music on, and thus received more songs. She explained that she did not send many songs, but preferred to see "what happened" in the system. B5 and B6 used the system the least and did not know any other participants in the study. B5 only used it to and from campus and encountered one other user, while B6 mostly used his player alone on the fourth floor, where he was isolated from the others. 
The ones who pushed most songs were C7 and C8 who always worked together. They pushed to each other, and "as soon as someone [of the others] appeared" in the vicinity. Together with A4, C7 and C8 spent most time on campus of the participants. Finally, the friends D9-D13 mostly used the system together and had a similar amount of shared songs. It was higher than A1-A4 who also knew each other from before, and one reason for this is that D9-D13 developed playful activities such as pushing songs as pranks.

\section{Social awareness}

Social awareness turned out to play a larger than expected role in the study. Many participants had the system on passively in the background even when they were not engaged in sharing or listening. One reason for this was to increase the probability of getting music, as B6 explains:

“... as you sit in school, you don't have to listen to it but you can... I had mine on anyway just in case anyone would pass by... by coincidence... so that you have a large probability of a [music] transfer to happen. I've had mine on every day, lying there, even if I didn't listen to it"

But another reason for keeping it on was simply curiosity and wanting to see if and when someone got connected. Every now and then the participants scanned the interface for people and new songs. For some, obtaining awareness of other users became an ordinary part of playing music, integrated with the usual activities of managing the music player and as unremarkable as glancing through a physical window to see what is outside. As D10 describes below, he would check the player when entering a new area, when turning it on or when taking the player out of the pocket/bag to change songs. His friend D9 follows up by suggesting that Push!Music could also be used simply as an awareness tool to see if friends are around in a crowded place:

D10: "But I think I checked a couple of times too when I got on the bus, you turn it on or you change songs, then you see if the lamp [indicating WiFi] of if the man [the icon indicating users nearby] were lit up, if there was anyone else on the bus..."

D9: "It would have been great if you know... like we go with bus 16 almost all of us and then you can see as you, there are so many people, as you enter the bus you could have the device to tell 'ah he's on the bus too",

What D9 suggests is that the system also introduces enhanced digital awareness of people around you; like the Hummingbird (Holmquist et al. 1999) it makes one aware of users not directly visible. D10 experienced this when he thought he was alone on campus and suddenly discovered another user nearby:

"I have found people who you wouldn't have seen if... who you hadn't even seen nearby... you've been in school alone and then suddenly you see there is this Mats or what it was... someone who was called... And it was completely dead in school, I had no idea where he was at all, there was only this person there somewhere..."

It clearly added to the excitement of using Push!Music that there were other unknown users nearby. Some participants saw the same unknown users several 
times or even daily, which gave them more time to make guesses or theories about who these users could be and where they were located on campus:

C8: “... I used some process of elimination when not many were there and some poor guy was out in the kitchen [there is one on each floor for students to use] or maybe it was a few people... I tried to look for PDAs but it didn't go so well..."

Interviewer: "So you wanted to know who the others were?"

C8: "Yes, at least I did... I'm a very curious person."

These theories became a popular topic of discussion among the participants, similar to what happened in the study of the Jukola system (O'Hara et al., 2004). This primarily concerned C7 and C8 (the tight pair) and A1-A4 (the group of class friends) who did not know each other but happen to be located on the same floor on campus. In the conversation below, A1, A2 and A4 are discussing C7 (Hans/Hansel) and her friend C8 (Greta/Gretchen) who they first believed were faked and not real users; partly because they always appeared visible and partly because of the intriguing and suspicious choice of nicknames:

A2: “... we thought Hans [Hansel] and Greta [Gretchen] were bots or something like that... they... they were two PDAs that were put in your office because of the name[s]..."

A1: "Plus, they were always visible too."

A2: "Yeah, those were the ones you saw, it was Hans and Greta, and Hans was kind of blinking..."

A1: "Is it them who sit in that room close to the coffee machine on the third floor? Those [two] who always sit there? That room that is kind of long, if you go from the coffee machine it is... Is it them?"

Interviewer: "Mm, yes."

A1: "I knew it!" [laugh]

A4: "Exactly."

A2: "Then we were right!"

C7 and C8 had made similar theories and assumptions about the group A1-A4. However, C7 and C8 clearly believed they gave enough cues to other users by frequently and visibly using their mobile devices. Below, $\mathrm{C} 7$ is also starting to wonder what the 'rules' of this technology are: if A1-A4 had figured out who she was, how come they did not push her any songs:

C8: "But I thought it was obvious because we always had the PDAs... how could they not see that?"

C7: "Yeah, exactly."

Interviewer: "I don't think they noticed."

C8: "I sat there and clicked hysterically [on the PDA] for some time... so it was MDI-people [from class A]? That's what I assumed... they do hang out there..."

C7: "Hm... how strange they didn't send me songs in that case..."

Despite the general curiosity about others, no actual face-to-face interaction took place between users who did not know each other before the study. They did 
push songs to strangers but there were no attempts made during the study to ask anyone or let someone know that you were a fellow participant.

The majority of the participants argued that a personally selected nickname is enough when sharing user information, as long as it could be used to simply recognise users you have met before. Having more information would imply that others as well as oneself could be looked up, and this was something they did not want everyone to be able to do. Some further argued that another possible implication of having more information, e.g. a picture, could be that it evokes prejudices that, in turn, affect the sharing of music negatively. This reveals a tension about identity in Push!Music, as music is usually much about expressing one's identity (see e.g. Brown et al., 2001):

B6: "I wouldn't want a picture... or to see any picture at all because [I] think it takes away some of the... you can still in some way make some judgement [about the received music] without "crap, he looks like a hard rock fan, I have to run away now to avoid getting music" or similar... it's not as spontaneous. You don't need to know who it is that you have shared music with, then you might get a more... then it is more fun to get music actually, when it is a totally anonymous... transfer [of music]"

C7: "I wouldn't probably push my music to a hard rock fan for example... if I see, oh, he looks like a hard rock fan, I would think that he wouldn't like..."

\section{Sharing music with friends}

The participants had different motivations for pushing songs to friends. The majority thought pushing was an exciting feature, and therefore pushed songs because they enjoyed it and did so as soon as someone they knew (or did not) was nearby. Two other motivations (also present in an earlier study, c.f. Håkansson et al. 2007) were to recommend a song because you thought the receiver would like it, or to disseminate a song because you liked it yourself and wanted others to hear. The latter demonstrates some impression management (Goffman, 1959), as the sender might pick a song to tell something about him/herself: "... I wanted to spread 'Hello Saferide' to as many [people] as possible because I like that artist... I think people should listen to this if they haven't discovered it before..." (A2). D10 imagines how he could use Push!Music to push songs and maintain his identity and role as someone who knows about new music before everyone else does:

"I look at different web sites, top-ten lists of the most popular downloads and those kind of things... everything that's new... and then you check almost every day to see what's popular today and if you see something you recognise then you get it... I know that I often see it before other people and then I could send it [using Push!Music] to other people earlier too... spread the word faster."

Another motivation was to push a song to get something to talk about as an important "side-effect". The sharing of music became a prompt for social interaction, but this happened only between users who already knew each other 
and were socialising face-to-face. In these cases, using Push!Music created a sense of togetherness:

A2: “... me and A3 talked a bit... we talked generally about music and so, because we both had Push!Music, and about me hearing the new [song] by Chemical Romance and then [she said] 'ah, but I've got that'..."

A3: "I was at their concert, it's my favourite band, I've got lots [of music] by them..."

A2: “'Ah, I've got that' she said and then maybe we pushed it to someone else..."

Yet another motivation was to push a "tasting sample" or a "memory aid' that would then help the receiver to remember getting more of that artist, for instance at an online shop. A number of participants talked about how difficult it is to remember recommendations you get from friends, as D10 gives an example of: "we face that problem almost every day, we talk about applications or anything on the web really, and then when you come home and you have time to check these [things] up, you have no idea what they were called."

A final and noticeable motivation was to push songs to friends as pranks. This was something that mainly happened in the group of five friends (D9-D13) who knew each other well. We did not see any 'mischievous' use of Push!Music aimed towards strangers. The friends easily knew the difference between serious recommendations and pranks, and sometimes they would not waste time listening to the latter - as D13 says: "Blixten [D10] sent me all the music he knew I wouldn't like. [laugh] So I deleted it as soon as it appeared..." Pranks were also in-jokes, which helped creating a social cohesion. An example of this was one song in particular that was mischievously disseminated to everyone in the group (D9-D13). No one appreciated it as a 'good' song, but everyone enjoyed the prank in itself.

D9: "I think it didn't take long before everyone had 'Boten Anna' [a song]..."

Interviewer: "Who had it from the beginning?"

D9: "Yeah, who had it? No, it was D11 who had it from the beginning..."

Interviewer: "Why did you send it?"

D11: "I knew D9 would think it was fun! [everyone laughs] When I put together the list [of song for the study] I thought, well, I think I'll add this one..." [laugh]

Despite the 'non-serious' music as a result of pranks, D9-D13 believed that one has a greater tolerance towards music received from friends compared to strangers, and that this should be addressed in the system.

\section{Sharing music with strangers}

Some motivations were the same as when pushing songs to friends, such as disseminating particular songs. However, we also found motivations that were different, and some reasons not to push to strangers at all.

Participants pushed songs as 'Hello, I'm here'-messages to strangers to let them know that they were around, as C7 explains: “... if I don't push him [a 
song], how will he know that I'm there?" They pushed songs to trigger some kind of contact, often as implicit requests for music to be pushed back. These actions could be combined with disseminating a particular song, but several users just picked a random song when pushing to a stranger, as C7 explains: "Well, I just picked a song. I don't know that person so I don't know what taste in music he has... if he likes my song then he'll save it and if not, he can remove it, it doesn't matter."

Another reason to push was to reciprocate to a song one had received earlier. By considering songs as gifts, we here became aware of the "obligation to reciprocate" that comes with received gifts (Taylor and Harper, 2002). In Push!Music reciprocity was sometimes problematic. For instance, a number of users told us that they wanted to reciprocate, only to realise that it was no longer possible because the sender had moved out of the WiFi range.

They also expressed reasons not to push songs to strangers. One reason not to push (pranks as well as 'serious' recommendations) was simply because one did not know the person. Another reason was that some believed it could be experienced as too intrusive. The participants in the conversation below compare pushing songs to strangers with spamming and looking for random contacts on ICQ:

D13: "It really depends [if I would push songs to strangers]... if you have some music that maybe you have made yourself or something... sending [it] to all kinds [of users] just to disseminate... but I don't think, "I like this band", I wouldn't spread to all sorts [only] to the ones you know..."

D9: "Exactly, I wouldn't sit on the bus and spread music, that feels like..."

D13: “...like spam"

D9: "I don't look for random contacts on ICQ either"

Yet another important reason why some did not want to push songs to strangers was that as a sender, you could not easily get any feedback on what the receiver thought about the music. Currently the only way would be to ask the recipient face-to-face, and as mentioned before no face-to-face interaction was initiated between users who did not know each other. A related and equally important concern was that you could not get credit for pushing great songs (without face-to-face interaction). Neither could you build up a reputation for possessing great music, or maintain your identity as a person with great taste. A1, who gave the impression of being a true music aficionado (and a keen user of online file sharing systems), was the one who strongest expressed this concern:

A1: "It feels like the concept of pushing only works if you know who you send to, so you can follow up on it later. Because, if the system grows and there are 5000 users, I don't see any motivation in using [the] push [function] at all, to push music to someone specific..."

Interviewer: "How do you mean?"

A1: "I don't get credit for sending that song! Nobody will care..."

Interviewer: "You want credit?" 
A1: "I want credit, yes, you want something. If it grows and gets really big I think you... the motivation to push music to people you don't know $[\ldots]$ then it is only interesting if you could perhaps build up some kind of reputation for pushing a lot of files or something..."

Participants acknowledged that pushing music to strangers could potentially be used as a trigger to get in touch with other people; however, they also brought up some concerns. In the discussion below, A2 claims that since the music is the most important part, he does not want any social consequences or obligations as a result of sharing music. Furthermore, he points out that if Push!Music were to be used as a means to get in touch with people, it would require everyone to have the same approach to avoid intrusiveness, similar to what Goffman (1963) calls mutual openness. That is, there has to be some (unspoken) mutual agreement that it is approved to engage in face-to-face encounters with unacquainted users:

A2: "It depends on how you use it [Push!Music], if you use it to meet... well, the music is the most interesting. I don't want to meet that person... maybe it's not that interesting to meet him, but maybe someone uses it as some social [device], "I want to meet people, I have no friends, but I listen to this music."'”

A3: "Maybe you want to meet people who have the same taste in music and discuss music?"

A2: "Then you have to be more... then you need to have such an approach to it, everyone needs that approach if [s/he] uses the service. I wouldn't like someone to... sure, it [Push!Music] can push some of my music, but I don't want any person to look me up because of that."

The participants had different opinions about the fact that in Push!Music, songs can only be shared with people in the vicinity. A1 stood out from the others and did not see any added value in sharing only with nearby users - factors such as bandwidth, convenience and size of download were more important. However, the majority of the participants were positive to ad hoc local sharing. Despite their doubtfulness about direct interaction with unknown users, they still believed it was an intriguing, fun and personal way of getting new music compared to if the same songs had been analysed and sent out via computer. A2, who also claimed that the music itself was the most central part to him, brings up the importance of context when receiving a song from another person. A3 adds that moving in changing contexts could mean that one gets different music:

A2: "Let's say this other person has said this [song] is good, someone else should listen to this too, that means something right? Who that person is. I would never look that person up because I've received a song from him as I passed him in the city, but since this person listens to it in his player and maybe rated it and says it's good, then you should listen to it. Just because it's from a person in that context is very important, it is more personal in a way... compared to if a computer would have analysed it..."

A3: "Then maybe you can get different songs, different amount of songs, depending on where you are?..."

C8, who was very curious of the other users during the study, thought it was intriguing to know that users of Push!Music are real persons around you: "It was more fun, I think, to have them [other users] 'live', because knowing that someone is nearby but you don't know who it is, that's more exciting! Then it's a 
physical person, not just a name on a display..." As B5 expresses below, the nearby or local could also be seen as a sort of security or as a filter, implying that you cannot get music from anyone or any kind of music. The local aspect is also what he believes makes Push!Music different to online sharing systems:

“... this local part is some kind of security in itself and fun too. For example if you are on the bus and suddenly you receive music, that's fun, someone [else] is here [on the bus]... but if it would be over a larger distance, then... then you're basically back on the internet again, then I would have feared that suddenly there would be some song with five minutes of recorded screams"

Overall, receiving music from strangers often meant a welcome break from your own music. According to the participants, this music was more unexpected than something friends would have sent them. The majority of the participants were positive about the music they had received from strangers, although in general they wished they had received more during the study.

\section{Sharing automatically}

Because of technical reasons, the participants did not experience any automatic recommendations during the study. Despite this, they all talked enthusiastically about the concept of automatic sharing and referred to it as the most fun and "magical" part of Push!Music. They primarily seemed to think of the automatic sharing as something that would occur between strangers.

We recognised two possible reasons why the automatic sharing was so highly appreciated. The first reason is that the automatic sharing allows users to become introduced to new music without being active. The majority of the participants wanted new music, but said that they were "lazy" and wished they were more active looking for it. Push!Music could provide you with inspiration to listen to new music without forcing you to type in or actively search (which requires you to know roughly what you are looking for), as it is done in most online sharing systems. As A2 told us: “...you put it [the mobile device] there and thought it could share music and then when you checked it you would have received something... or sent something."

The second reason is that the automatic sharing could be looked upon as a more balanced way of sharing compared to directly pushing songs, which could be experienced as too intrusive. The automatic way would then allow the sharing of music among people in a non-intrusive but yet personal way. In the conversation below, A2 wants to specify which songs to share (as if he were to push them), but he wants the system to share them automatically and thereby diminish his role and responsibility in the act of sharing to strangers:

A1: "You trust it [the system] to get something automatically, because... I don't know, I don't get much out of pushing a song to someone I don't know, who I cannot ask afterward if he liked the song, it feels pointless [to push], it was fun at first to know now I've pushed a song, 
I've spread 'Mäster spettaren' [a particular song] to five people [laugh], but that's about it what I can be satisfied with..."

A3: "But if you're with friends, ahh, have you heard that song, you can have it from me and you send it over and it's done really fast... that's when you're going to use [the] push [function]. But like he [A1] said, in the beginning it was fun to send stuff."

A2: "I would have liked a function: ok, I want to spread this song by Hello Saferide, so it's labelled "please push this when I meet someone" instead of... ok, I can see Hans but I don't know who it is, [so] I can't push to him, I don't know that person, but if I tell it [the system] to push this [song] if it meets people, then it will spread it [the song] to people..."

Interviewer: “... kind of automatically, but yet personal?"

A2: "Yeah, exactly, you decide what... then it can be random if it [the system] pushes or not [...] instead of this active [the current push function] which you only use for... those who sit beside you or similar."

\section{Implications for mobile media sharing systems}

Push!Music was deliberately designed as an open system with few limitations. Users could push a song to any user in the vicinity, and there were no restrictions from who one could receive music - if someone pushes you a song, it will end up in your playlist. However, this openness was less than straightforward from a social perspective. Push!Music was quickly adopted by the participants to support already existing social networks and practices. For instance, users got a stronger social cohesion by using Push!Music to send songs as pranks or to prompt discussions about music and related things. Although the participants also pushed songs to strangers, this was something they did not feel equally comfortable with; for example, they argued that one "cannot" push to someone one does not know, and if one did, some worried that the recipient would think it was too intrusive.

We recognised a division in the use of Push!Music: users enjoyed being active with friends (sending songs as pranks, memory aids, recommendations, etc.) and felt most comfortable with the idea of being passive with strangers (sharing automatically). Perhaps this is not surprising, as we naturally do not have the same relationship with strangers as with friends. For instance, we do not greet or interact with strangers in public and densely populated areas because it would simply be too exhausting and overwhelming (Goffman, 1963). Nonetheless, we are still curious and intrigued about unknown people around us, and we can use this knowledge to build systems that enhance our sense of our surroundings (Paulos and Goodman, 2004). The fact that the participants talked enthusiastically about the idea of sharing automatically with people one encounters in everyday life is a demonstration of this.

The following design implications draw on the findings in the study. They are not only applicable to music sharing; we argue they have relevance for mobile media sharing in general, e.g. for digital photos. 


\section{Allow division into active and passive use}

Most of the participants used Push!Music differently with friends vs. strangers. This suggests that media sharing activities could be divided into two separate parts: one active for friends, and one passive for strangers. This could ensure an enjoyable and secure experience of media sharing in the mobile realm. Similar to IM systems (see e.g. Grinter and Palen, 2002), the use of buddy lists could allow users to add people as friends or contacts to a particular list where pushing of songs and sharing of personal information is possible. Strangers encountered in everyday life would not be included in this list by default. It should still be possible to push songs to strangers, but it would require some sort of approval from the receiver before the song is actually sent. However, the system would still be open for sharing music automatically between strangers, which would provide users with new music in a non-intrusive and less socially demanding way. Moreover, we suggest that the active part could be extended to allow for sharing over larger distances, to support a more spontaneous sharing between friends who are not in the vicinity. After all, friends play a very important part in music sharing, implying that they should be possible to share with at anytime.

\section{Enhance the awareness of who, where and when}

Push!Music currently lets users know who has sent a particular song and if it was pushed or automatically shared. However, the system did not provide any notice when another user appeared in the vicinity or, importantly, when one received (or automatically sent) a song. We learned two things: firstly, as a result of this, users were sometimes unaware of the fact that they had received songs and did not notice them until later. Secondly, users talked about the importance of receiving music from "a person in that context", arguing that the setting or situation in which one gets a song is important and matters to the overall experience of sharing music. When evaluating a mobile social software system for motorcyclists, the researchers found that an exciting part of the experience was to hear a notification sound when one encountered another biker and some content was transferred (Esbjörnsson et al., 2004). We therefore suggest enhancing the awareness of who, where and when with a vibration or sound (which should be possible to turn off). Such a notification would give the receiver a chance to know when others are around, to "be prepared" to listen to something new, and finally, a chance to reciprocate while the sender is still in the vicinity.

\section{Support reciprocity}

As Taylor and Harper (2002) report on gift-giving in their study of teenage mobile phone use, accepting a gift (for example a text message) means that the recipient is "obliged to reciprocate in kind". In our study of Push!Music, we also became aware of this obligation in the sharing of music, and how participants sometimes became frustrated when they could not reciprocate due to design and 
technical issues. This applied to the sharing with friends as well as with strangers. The ad hoc communication with users moving out of the WiFi range or one not noticing the received music until later made reciprocity difficult. As reciprocity has proved to be an essential part of the sharing of music using Push!Music, we suggest that there should be support for reciprocity to better support the practice of sharing. This could include improved methods for sharing media back, or simply sending a "thank you" to acknowledge a received song.

\section{Support identity and impression management}

We noticed a tension in Push!Music where the participants on one hand claimed that identity and impression management did not matter (it was the sharing of music that was important, not with whom) versus a strong wish for better support for it. For example, we learnt that for some users, getting credit was a very important motivation behind the sharing of music. Some users wanted to be able to build up a reputation for pushing good music or for being the first ones who disseminate new music. Although the majority of potential users might be 'average' consumers who just want to get to know new music, we recognise the need to better support music aficionados and their role in the system. We argue that they are important in sharing systems because it is through them that a lot of the sharing of music takes place. We therefore suggest a better support for maintaining one's identity and impression, and a better support to recognise other users. However, in a mobile sharing system, this puts other demands on privacy compared to online systems, which in turn limits how the impression management could be supported. We suggest that such information could be some sort of 'abstract accountability', similar to ambiguous awareness information that Gaver (2002) proposes or how the presence of familiar strangers is presented in (Paulos and Goodman, 2004).

\section{Conclusions}

In our study of the Push!Music system, we found that rather than triggering new face-to-face interactions with strangers, the system mainly supported existing social networks. At the same time, users did occasionally share songs with strangers - but would have preferred automatic sharing, as it implied less social intrusion. We believe that the findings could be valuable to the design of mobile media sharing systems in general, not just the ones related to music. For instance, people are happy to publish photos on on-line systems such as Flickr (wwwflickr.com), but are likely to use access management to exercise control over which photos are available to everyone in the world, and which are only available to close friends or family. Mobile sharing systems cannot simply allow sharing with everyone who happens to be in the same location, but at the same 
time, the presence of other users (or as one subject expressed it, "real people") was an exciting part of the experience of Push!Music and made the sharing feel more "live". Support for reciprocity in gift-giving, identity management, and credits for advanced users who contribute to the system are also important factors for the success of future mobile media sharing systems - perhaps even more so than for existing stationary applications.

\section{Acknowledgments}

We would like to thank our project colleague Mattias Jacobsson for help with practical issues and overall feedback. We would also like to thank Alex Taylor, Barry Brown and colleagues at the Viktoria Institute for very thoughtful and valuable comments on this paper and earlier work. Finally, thanks to the study participants for their time and enthusiasm. This work is supported by the ECAgents project (IST-2003-1940) funded by the European IST-FET programme.

\section{References}

Bassoli, A., Moore, J., and Agamanolis, S. (2006): 'tunA: Socialising Music Sharing on the Move', in K. O'Hara and B. Brown (eds.) Consuming Music Together: Social and Collaborative Aspects of Music Consumption Technologies, Springer, pp. 151-172.

Bly, S., Harrison, S., and Irwin, S. (1993): 'Media Spaces: Bringing People Together in a Video, Audio, and Computing Environment', in Communications of the ACM, January 1993, Vol. 36, No. 1, pp. 27-47.

Borovoy, R., Martin, F., Vemuri, S., Resnick, M., Silverman, B. and Hancock, C. (1998): Meme Tags and Community Mirrors: Moving from Conferences to Collaboration. Proceedings of CSCW'98, ACM Press, New York.

Brown, B., Sellen, A., and Geelhoed, E. (2001): 'Music sharing as a computer supported collaborative application', in Proceedings of ECSCW 2001. Kluwer Academic Publishers, pp.179-198.

Bull, M. (2000): Sounding Out The City, Berg, NY, USA.

Bull, M. (2006): 'Investigating the Culture of Mobile Listening: From Walkman to iPod' in K. O'Hara and B. Brown (eds.) Consuming Music Together: Social and Collaborative Aspects of Music Consumption Technologies, Springer, pp. 131-149.

D'Arcangelo, G. (2005): The New Cosmopolites: Activating the Role of Mobile Music Listeners. Presented at the 2nd International Mobile Music Workshop, at the 2005 "New Interfaces for Musical Expression" Conference, University of British Columbia, Vancouver, BC.

DeNora, T. (2000): Music in Everyday Life, Cambridge University Press, Cambridge, UK.

Dourish, P. and Bellotti, V. (1992): 'Awareness and Coordination in Shared Workspaces', in Proceedings of CSCW'92, Toronto, Ontario, pp 107-114. New York: ACM.

Eagle, N. and Pentland, A. (2005): 'Social Serendipity: Mobilizing Social Software', in IEEE Pervasive Computing, vol. 4, no. 2, 2005, pp. 28-34.

Esbjörnsson, M., Juhlin, O. and Östergren, M. (2004): 'Traffic Encounters and Hocman Associating Motorcycle Ethnography with Design', in Personal and Ubiquitous Computing, Springer Verlag, vol. 8, no. 2, pp. 92-99. 
Gaver, B. (2002): 'Provocative awareness', in Computer Supported Cooperative Work, Kluwer Academic Publishers, the Netherlands, Vol. 11, 2002, pp. 475-493.

Grinter, R.E. and Palen, L. (2002): 'Instant Messaging in Teen Life', in Proceedings of CSCW 2002, New Orleans, USA.

Goffman, E. (1959): The Presentation of Self in Everyday Life. Anchor Books, New York.

Goffman, E. (1963): Behavior in Public Places. Notes on the Social Organization of Gatherings, The Free Press, New York, USA.

Holmquist, L.E., Falk, J., and Wigström, J. (1999): 'Supporting Group Collaboration with Interpersonal Awareness Devices', in Personal Technologies, vol. 3, nos. 1-2, 1999, pp. 105-124.

Håkansson, M., Jacobsson, M., and Holmquist, L.E. (2005): 'Designing a Mobile Music Sharing System Based on Emergent Properties', in Proceedings of AMT 2005, Takamatsu, Japan.

Håkansson, M., Rost, M., Jacobsson, M. and Holmquist, L.E. (2007): 'Facilitating Mobile Music Sharing and Social Interaction with Push!Music', in Proceedings of HICSS-40, Hawaii, USA, 2007.

Jacobsson, M., Rost, M., and Holmquist, L.E. (2006): 'When Media Gets Wise: Collaborative Filtering with Mobile Media Agents', in Proceedings of IUI 2006. Sydney, Australia.

Jacobsson, M., Rost, M., Håkansson, M., Holmquist, L.E. (2005): 'Push!Music: Intelligent Music Sharing on Mobile Devices', in Adjunct Proceedings of UbiComp 2005, Tokyo, Japan.

Jaques, R. Cameraphone users fail to click with MMS. Personal Computer World, 08 Feb 2006.

Jung, Y., Blom, J., and Persson, P. (2006): 'Scent Field Trial - Understanding Emerging Social Interaction', in Proceedings of MobileHCI 2006, Helsinki, Finland.

McCarthy, J.F. and Anagnost, T.D. MusicFX: An Arbiter of Group Preferences for Computer Supported Collaborative Workouts. In Proceedings of CSCW '98, ACM Press, New York.

O'Hara, K. and Brown, B. (2006): Consuming Music Together: Introduction and Overview, in K. O'Hara and B. Brown (eds.) Consuming Music Together: Social and Collaborative Aspects of Music Consumption Technologies, Springer, pp. 3-17.

O’Hara, K., Lipson, M., Jansen, M., Unger, A., Jeffries, H., and Macer, P. (2004): 'Jukola: Democratic Music Choice in a Public Space', in Proc of DIS2004, Cambridge, MA, USA.

Paulos, E. and Goodman, E. (2004): 'The Familiar Stranger: Anxiety, Comfort, and Play in Public Places', in Proceedings of CHI 2004, Vienna, Austria.

Taylor, A.S., and Harper, R. (2002): 'Age-old Practices in the 'New World': A study of giftgiving between teenage mobile phone users', in Proc of CHI 2002, Minneapolis, USA.

Voida, A., Grinter, R.E., Ducheneaut, N., Edwards, W.K., and Newman, M.W. (2005): 'Listening in: Practices surrounding iTunes music sharing', in Proc of CHI 2005. Portland, USA.

Want, R., Hopper, A., Falcao, V., Gibbons, J. (1992): The Active Badge Location System. ACM Trans. on Inf. Sys., Jan.1992.

Weilenmann, A. (2001): 'Negotiating Use: Making Sense of Mobile Technology', in Personal and Ubiquitous Computing, vol. 5: (2), 137-145 Springer-Verlag London Ltd.

Östergren, M., and Juhlin, O. (2006): 'Car Drivers using Sound Pryer - Field Trials on Shared Music Listening in Traffic Encounters', in K. O'Hara and B. Brown (eds.), Consuming Music Together: Social and Collaborative Aspects of Music Consumption Technologies. Springer, 2006, pp. 173-190. 